\title{
Correlation between weather and incidence of selected ophthalmological diagnoses: a database analysis
}

This article was published in the following Dove Press journal:

Clinical Ophthalmology

22 August 2016

Number of times this article has been viewed

\author{
Christoph Kern \\ Karsten Kortüm \\ Michael Müller \\ Florian Raabe \\ Wolfgang Johann Mayer \\ Siegfried Priglinger \\ Thomas Christian Kreutzer \\ University Eye Hospital Munich, \\ Faculty of Medicine, Ludwig- \\ Maximilians-Universität München, \\ Munich, Germany
}

Purpose: Our aim was to correlate the overall patient volume and the incidence of several ophthalmological diseases in our emergency department with weather data.

Patients and methods: For data analysis, we used our clinical data warehouse and weather data. We investigated the weekly overall patient volume and the average weekly incidence of all encoded diagnoses of "conjunctivitis", "foreign body", "acute iridocyclitis", and "corneal abrasion". A Spearman's correlation was performed to link these data with the weekly average sunshine duration, temperature, and wind speed.

Results: We noticed increased patient volume in correlation with increasing sunshine duration and higher temperature. Moreover, we found a positive correlation between the weekly incidences of conjunctivitis and of foreign body and weather data.

Conclusion: The results of this data analysis reveal the possible influence of external conditions on the health of a population and can be used for weather-dependent resource allocation.

Keywords: corneal injury, trauma, uveitis, conjunctivitis, weather

\section{Introduction}

Several studies in other disciplines of medicine have established the influence of weather on patient volume or the incidence of diseases in emergency rooms. ${ }^{1-3}$ A Chinese study has revealed more emergency department visits during higher temperatures and heat waves. ${ }^{4}$ Moreover, the incidence of specific diagnoses has been correlated with meteorological data. One study has shown significant effects of cold and windy weather on the incidence of emergency calls regarding acute coronary syndrome or symptoms of elevated arterial blood pressure in an emergency medical service. ${ }^{2}$ Indeed, not only emergency medical service data but also emergency calling center data have shown that cold weather is often correlated with a higher incidence of hypertensive emergencies and acute coronary syndrome. ${ }^{1,2}$

A higher incidence of diseases is related not only to colder and windy weather but also to warmer weather. The amount of infectious diseases and headaches is increased during warm weather. ${ }^{5,6}$ To date, only two studies exist with regard to a correlation between patient volume or incidences and weather data in ophthalmological emergency rooms, namely, for the diagnosis "acute iridocyclitis", which shows an increased incidence during colder weather, especially in the winter months. ${ }^{7,8}$

Since October 2012, all patient contacts in our emergency department have been recorded digitally in a custom-made electronic health record ${ }^{9}$ All findings are exported into a data warehouse called the Smart Eye Database (SMEYEDAT), including clinical 
data (eg, diagnoses, visit date, and visual acuity). By means of this database, we have the opportunity to monitor the daily patient volume and the incidence of selected urgent diagnoses during the period between January 2014 and July 2015.

Based on the availability of these data, we have posed the question as to whether meteorological data influence urgent ophthalmological disease. To answer this question, we correlated the overall patient volume and the incidence of major ophthalmological diseases coded by the International Classification of Diseases, Tenth Edition (ICD-10) in our emergency department with selected weather data. ${ }^{10}$ The aim of this study has thus been to examine a potential correlation between ophthalmological conditions and selected weather variables.

\section{Patients and methods}

\section{Patients}

A SMEYEDAT query for patients treated for "conjunctivitis" (H10.x), "foreign corneal body" (T15.0), "acute and subacute iridocyclitis" (H20.x), and "corneal abrasion" (S05.0) between January 1, 2014, and July 31, 2015, was performed (ICD-10 codes are given in brackets). Data were exported in a spreadsheet for further statistical analysis. Only patients treated in our emergency department were included in the analysis. We performed a retrospective analysis with the collected data from our Smart Eye Database. Each visit of patients with the four ophthalmological emergency diagnoses was considered. Ethical approval was not required by the Institutional Review Board of University Eye Hospital Munich as this was a retrospective study. Every patient admitted to our hospital signs a consent that his data can be used for research.

\section{Meteorological data}

The weather data were obtained from the "Deutscher Wetterdienst" (German Meteorological Office) and represent the data from the weather station at Munich airport. The dataset included hourly measurements of temperature $\left({ }^{\circ} \mathrm{C}\right)$ and wind speed $(\mathrm{m} / \mathrm{s})$ to calculate the daily average. The sunshine duration in hours per day was also recorded. All weather parameters were measured $2 \mathrm{~m}$ above the ground. ${ }^{11}$ The exported data from the German Meteorological Office were imported into our data warehouse.

\section{Statistics}

To determine a possible correlation between the clinical variables (overall patient volume and incidence) and weather data, a Spearman's rank correlation test was used. The advantages of this method are that a determination of statistical distribution is unnecessary and it is unsusceptible to aberrations. The analysis reveals the Spearman's rank correlation coefficient "rho" $(\rho)$, with its rank being located between $(-1,1)$ and explains the strength and direction of a correlation. Moreover, a $P$-value is calculated. It refers to the probability that the null hypothesis ("the weather has no influence on clinical variables") is falsely accepted. A statistically significant result is assumed, if the $P$-value is $\leq 0.05$. Because of the relatively low level of psychological strain associated with the selected urgent ophthalmological diseases, the presentation of the patient does not take place immediately. We therefore cannot match the onset of symptoms with the day of first presentation. In addition, during working days, many private clinics undertake the treatment of the selected diseases. To minimize the influence of aberrations between working days and weekends, we used the weekly mean value of the clinical variable for further evaluation. Therefore, the weather variable had to be adapted to a period of 1 week. We calculated the total number of sunshine hours per week and the weekly mean of the temperature and the wind speed in order to correlate these meteorological data with the incidence of the selected ophthalmological urgent diagnoses.

In addition to the incidence of diseases, SMEYEDAT delivered the mean age and sex of the selected patients. A Wilcoxon signed-rank test was performed to examine a possible association of specific diagnosis with males or females. $P \leq 0.05$ was regarded as statistically significant.

For all statistical analysis, the free software environment " $\mathrm{R}$ " was used (Version 3.2.2, available online https://www.r-project.org/).

\section{Results}

In the period between January 1, 2014, and July 31, 2015, 34,931 patients were treated in our emergency department. Figure 1 shows an overview of the daily average patient count for the observation period. The $x$-axis shows the timeline in days and the $y$-axis shows the number of persons per day.

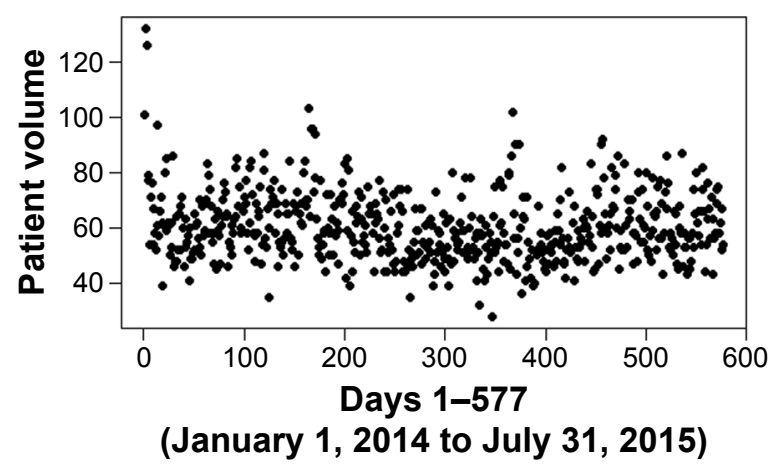

Figure I Daily mean patient volume during observation period. 
Table I Characteristics and number of patients between January I, 20I4, and July 3I, 2015

\begin{tabular}{lllll}
\hline & Incidence, $\mathbf{n}$ & Male:female, $\mathbf{n}(\%)$ & $\begin{array}{l}\text { Sex ratio } \\
\text { (male:female) }\end{array}$ & $\begin{array}{l}\text { Average } \\
\text { age } \pm \text { SD }\end{array}$ \\
\hline Total patient volume & $34,93 \mid$ & $18,523(53): 16,406(47)$ & $1: 1$ & $47.5 \pm 21.7$ \\
Conjunctivitis & 3,379 & $1,583(47): 1,796(53)$ & $0: 9$ & $37.5 \pm 20.9$ \\
Foreign body in cornea & 1,591 & $1,468(92): 123(8)$ & $11: 9$ & $37.8 \pm 13.6$ \\
Iridocyclitis & 597 & $279(47): 318(53)$ & $0: 9$ & $48.5 \pm 18.5$ \\
Corneal abrasion & 1,462 & $902(62): 506(38)$ & $1: 8$ & $37.1 \pm 20.3$ \\
\hline
\end{tabular}

Abbreviation: SD, Standard deviation.

The minimum number of patients per day was 28 , whereas the maximum was 132 . The mean value was 58 patients with a standard deviation of 12.54 patients.

The four selected ophthalmological emergency diagnoses were recorded 7,029 times. Table 1 shows the incidence of our diagnoses, the distribution of males and females including the sex ratio, and the average age with standard deviation. Regarding all diagnosed conjunctivitis and iridocyclitis, Table 2 provides an overview over the distribution of the subgroups. The material of "foreign bodies in cornea" was not recorded. The Wilcoxon signed-rank test showed a statistically significant difference between the weekly incidence of males and females suffering a foreign body in cornea (median male incidence per week $\pm \mathrm{SD}$ [17 \pm 6.5$]$; median female incidence per week $[1 \pm 1.2] ; P \leq 0.01)$.

The Spearman's rank test showed a statistically significant correlation between the overall patient volume and the two weather variables. An increase of the weekly sunshine hours led to a higher number of patients $(\rho=0.44, P \leq 0.01$; Figure 2). Moreover, a correlation between patient volume and higher weekly average temperature was detected ( $\rho=0.29, P \leq 0.01$; Figure 3 ). As seen in the graph, an increase in one sunshine hour per week led to one additional patient in the same period. Furthermore, a weekly average

Table 2 Subdivision of all diagnosed conjunctivitis and iridocyclitis

\begin{tabular}{|c|c|c|}
\hline Diagnosis (ICD- 10 code) & Incidence, $\mathbf{n}$ & $\%$ \\
\hline Mucopurulent conjunctivitis $(\mathrm{HIO.0})$ & 530 & 15.7 \\
\hline Acute atopic conjunctivitis (HIO.I) & 347 & II.I \\
\hline Other acute conjunctivitis ( $\mathrm{H} I 0.2)$ & 503 & 14.9 \\
\hline Unspecified acute conjunctivitis $(\mathrm{H} \mid 0.3)$ & 133 & 3.9 \\
\hline Chronic conjunctivitis ( $\mathrm{HIO.4})$ & 49 & 1.5 \\
\hline Blepharo conjunctivitis ( $\mathrm{HI} 0.5)$ & 70 & 2.1 \\
\hline Other conjunctivitis $(\mathrm{HI} 0.8)$ & 1,278 & 37.8 \\
\hline Unspecified conjunctivitis (HI0.9) & 445 & 13.2 \\
\hline Acute and subacute iridocyclitis $(\mathrm{H} 20.0)$ & 466 & 78.3 \\
\hline Chronic iridocyclitis $(\mathrm{H} 2 \mathrm{O} . \mathrm{I})$ & 31 & 5.2 \\
\hline Lens-induced iridocyclitis ( $\mathrm{H} 20.2)$ & 0 & 0 \\
\hline Other iridocyclitis $(\mathrm{H} 20.8)$ & 21 & 3.5 \\
\hline Unspecified iridocyclitis $(\mathrm{H} 20.9)$ & 77 & 12.9 \\
\hline
\end{tabular}

Abbreviation: ICD-10, International Classification of Diseases, Tenth Edition. temperature that was higher by $1^{\circ} \mathrm{C}$ means 2.6 more patients per week in our emergency clinic. No correlation was detected between patient numbers and average wind speed per week (Table 3).

For the weekly incidence of conjunctivitis, the Spearman's test revealed significantly more patients, when the weekly sunshine duration increased ( $\rho=0.46, P \leq 0.01$; Figure 4 ) and when a higher weekly average temperature prevailed ( $\rho=0.27, P=0.012$; Figure 5 ). A gain of $3 \mathrm{~h}$ sunshine per week led on average to one more patient suffering from conjunctivitis. An average increase of $3^{\circ} \mathrm{C}$ per week resulted in two more patients with the diagnosis "H10.x" being seen per week. No correlation was found for the weekly average wind speed. An overview of the results concerning the diagnosis of conjunctivitis is given in Table 4.

Moreover, the Spearman's rank test showed a statistically significant correlation between the weekly incidence of foreign corneal bodies and two weather variables (Table 5). Increased weekly sunshine hours ( $\rho=0.31, P \leq 0.01$; Figure 6) and an augmented weekly average temperature $(\rho=0.56$, $P \leq 0.01)$ resulted in a higher number of foreign bodies in cornea cases (Figure 7). One more patient with a foreign corneal body per week was seen, when a weekly increase of one sunshine hour or $2^{\circ} \mathrm{C}$ was recorded. No significant correlation was detected for the weekly average wind speed. All results are presented in Table 4.

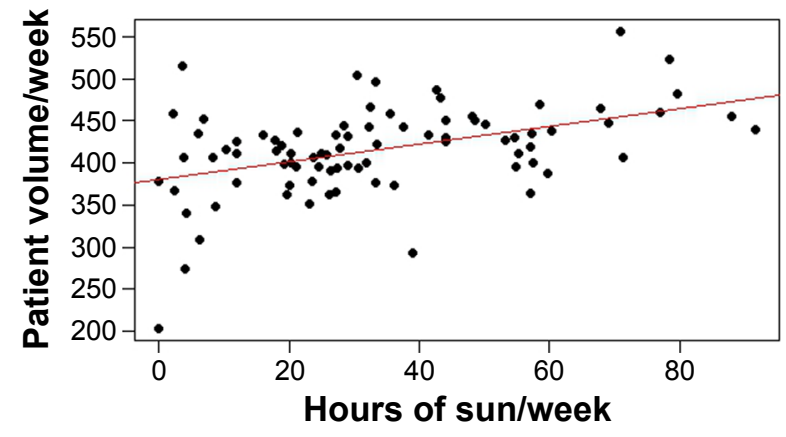

Figure 2 Spearman's correlation graph between the weekly patient volume and the weekly sunshine duration (hours) per week. 


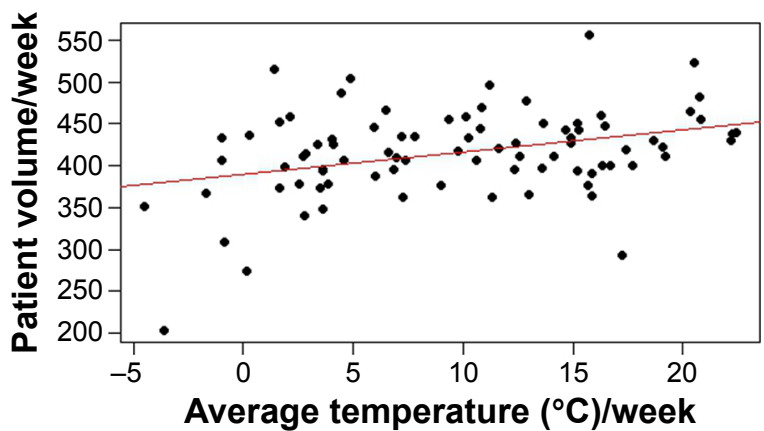

Figure 3 Spearman's correlation graph between weekly patient volume and weekly average temperature.

For the weekly incidence of the diagnosis iridocyclitis (Table 6) and corneal abrasion (Table 7), the Spearman's rank test revealed no statistically significant correlations.

\section{Discussion}

In this study, we observed higher patient numbers during weeks with an increasing average temperature or sunshine duration. A GPS tracking study in Japan showed that the movement profiles of a population are dependent upon the weather. ${ }^{12}$ In total, 31,855 GPS profiles were analyzed over a period of 1 year. The movement radius of the population on cold days (average temperature between $-5^{\circ} \mathrm{C}$ and $+5^{\circ} \mathrm{C}$ ) was significantly lower, and the people spent more time indoor (eg, at home, in restaurants, and in shopping malls). If this finding is transferred to our population, an explanation for decreasing patient numbers during weeks with a lower weekly average temperature can be provided. People are more likely to stay indoors, and the emergency department might be too far outside the "bad weather movement radius". As the evaluated diagnoses do not represent life-threatening diseases, patients might have a comfort zone, with some discomfort being tolerated.

Another study has correlated the daily distance covered by individuals with weather data. ${ }^{13} \mathrm{~A}$ gain in the average temperature leads to a higher distance covered. On the other hand, rainfall decreases the daily walking distance. Furthermore, a larger movement radius and a higher daily distance covered are found in outdoor activities, which carry a higher risk of injury. This could be another explanation for

Table 3 Spearman's correlation between the weekly overall patient volume and the average weekly weather data

\begin{tabular}{lll}
\hline $\begin{array}{l}\text { Patient } \\
\text { volume }\end{array}$ & $\begin{array}{l}\text { Correlation } \\
\text { coefficient }(\rho)\end{array}$ & P-value \\
\hline Sunshine duration & 0.44 & $\leq 0.01$ \\
Temperature & 0.29 & $\leq 0.01$ \\
Wind speed & -0.17 & 0.118 \\
\hline
\end{tabular}

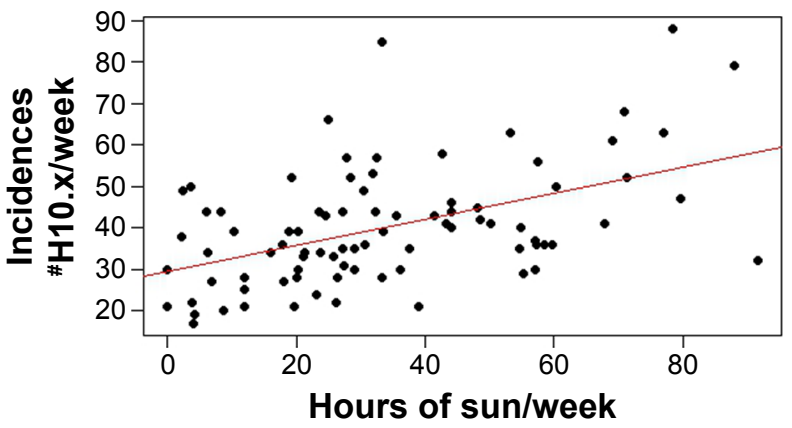

Figure 4 Spearman's correlation graph between the weekly incidence of conjunctivitis and the weekly sunshine duration (hours). Note: "ICD-10 code.

Abbreviation: ICD-10, International Classification of Diseases, Tenth Edition.

the correlation between higher patient numbers and increasing average temperatures or sunshine hours. Moreover, the higher number of foreign corneal bodies during better weather can be explained on the basis of the higher risk of injury occurring during outdoor activities. ${ }^{13}$

A statistically significant accumulation of the incidence of foreign body in cornea was found for males. Of all diagnoses coded as T15.0, 38\% (=607 cases) were declared as occupational accidents, among which 600 patients were male. Compared with all other patients, only $7 \%$ of all other cases were declared as industrial accidents. Thus, we concluded that a foreign corneal body is a typical occupational accident. According to the statistics of the "Statistisches Bundesamt Deutschland" (Federal German Office for Statistics), the building industry is the industry with the lowest number of female employees $(15 \%) .{ }^{14}$ Moreover, fewer people work in the building sector during winter time. This might be another explanation for the higher incidence of T15.0 during periods of higher average sunshine and temperature and the association with males.

As a selection criterion for the diagnosis of conjunctivitis, we used the ICD-10 code H10.x, which included all kinds of

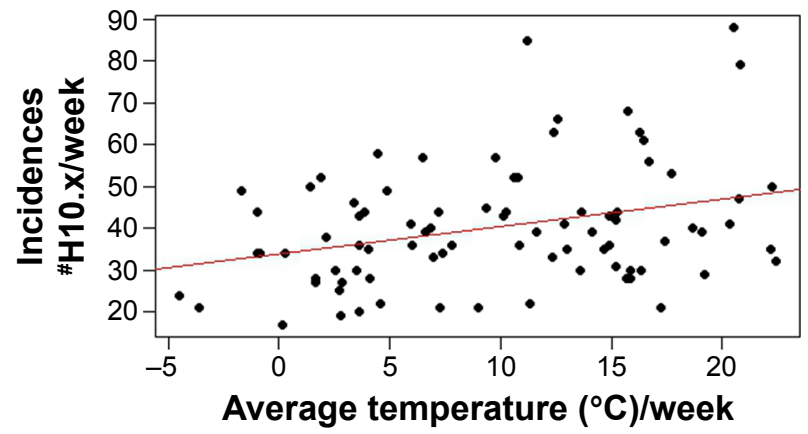

Figure $\mathbf{5}$ Spearman's correlation graph between the weekly incidence of conjunctivitis and the weekly average temperature.

Note: $\#$ ICD- 10 code.

Abbreviation: ICD-10, International Classification of Diseases, Tenth Edition. 
Table 4 Spearman's correlation between the weekly incidence of conjunctivitis and the average weekly weather data

\begin{tabular}{lll}
\hline $\begin{array}{l}\text { Conjunctivits } \\
(\mathbf{H} 1 \mathbf{0 . x})^{\#}\end{array}$ & $\begin{array}{l}\text { Correlation } \\
\text { coefficient }(\rho)\end{array}$ & P-value \\
\hline Sunshine duration & 0.46 & $\leq 0.01$ \\
Temperature & 0.27 & 0.012 \\
Wind speed & -0.17 & 0.125 \\
\hline
\end{tabular}

Note: \#ICD-10 code.

Abbreviation: ICD-10, International Classification of Diseases, Tenth Edition.

Table 5 Spearman's correlation between the weekly incidence of foreign body in cornea and the average weekly weather data

\begin{tabular}{lll}
\hline $\begin{array}{l}\text { Foreign body in } \\
\text { cornea (TI 5.0) }\end{array}$ & $\begin{array}{l}\text { Correlation } \\
\text { coefficient }(\rho)\end{array}$ & P-value \\
\hline Sunshine duration & $0.3 \mathrm{I}$ & $\leq 0.0 \mathrm{I}$ \\
Temperature & 0.56 & $\leq 0.0 \mathrm{I}$ \\
Wind speed & -0.17 & 0.133 \\
\hline
\end{tabular}

Note: ${ }^{*}$ CDD-10 code.

Abbreviation: ICD-10, International Classification of Diseases, Tenth Edition.

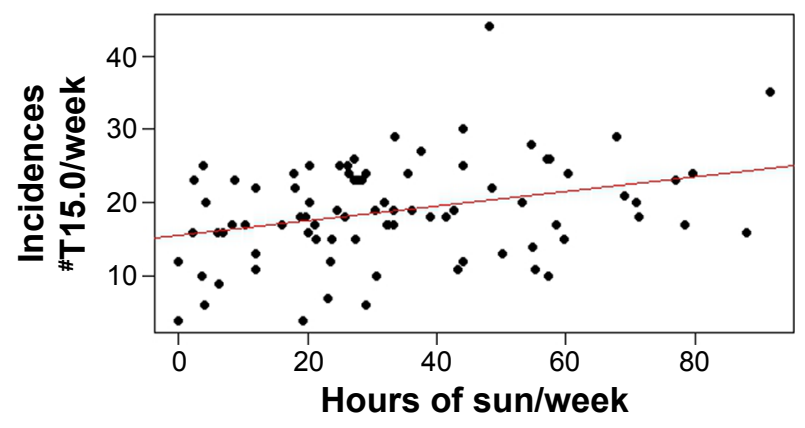

Figure 6 Spearman's correlation graph between the weekly incidence of foreign body in cornea and the weekly sunshine duration (hours).

Note: "ICD-10 code.

Abbreviation: ICD-10, International Classification of Diseases, Tenth Edition.

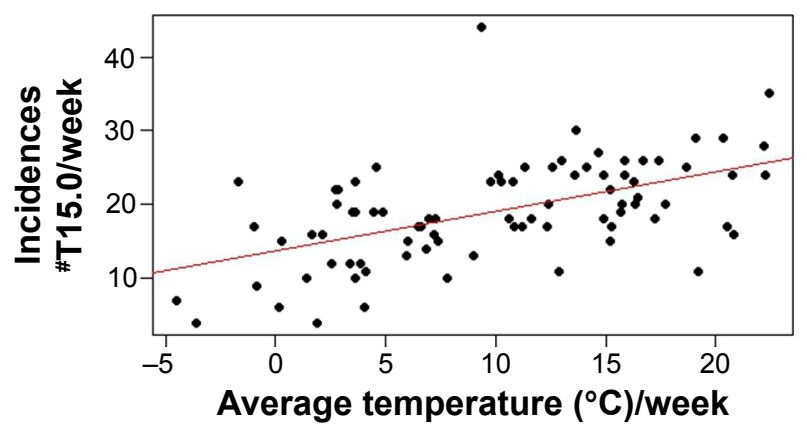

Figure 7 Spearman's correlation graph between the weekly incidence of foreign body in cornea and the weekly average temperature.

Note: \#ICD-I 0 code.

Abbreviation: ICD-10, International Classification of Diseases, Tenth Edition.

conjunctivitis in the analysis (allergical, bacterial, and viral). Allergic conjunctivitis is considered to be an important factor for the positive correlation between conjunctivitis and the increase in sunshine and temperature. The incidence of allergic conjunctivitis is significantly higher during pollination
Table 6 Spearman's correlation between the weekly incidence of iridocyclitis and the average weekly weather data

\begin{tabular}{lll}
\hline $\begin{array}{l}\text { Iridocyclitis } \\
(\mathbf{H 2 0 . x})^{\#}\end{array}$ & $\begin{array}{l}\text { Correlation } \\
\text { coefficient }(\rho)\end{array}$ & P-value \\
\hline Sunshine duration & 0.00 & 0.988 \\
Temperature & -0.09 & 0.430 \\
Wind speed & -0.18 & 0.101 \\
\hline
\end{tabular}

Note: \#ICD-10 code.

Abbreviation: ICD-10, International Classification of Diseases, Tenth Edition.

Table 7 Spearman's correlation between the weekly incidence of corneal abrasion and the average weekly weather data

\begin{tabular}{lll}
\hline $\begin{array}{l}\text { Corneal } \\
\text { abrasion (S05.0)\# }\end{array}$ & $\begin{array}{l}\text { Correlation } \\
\text { coefficient }(\rho)\end{array}$ & P-value \\
\hline Sunshine duration & 0.01 & 0.931 \\
Temperature & 0.03 & 0.759 \\
Wind speed & 0.01 & 0.912 \\
\hline
\end{tabular}

Note: ${ }^{I}$ CD-10 code.

Abbreviation: ICD-10, International Classification of Diseases, Tenth Edition.

and days of higher air pollution (eg, ozone). ${ }^{15-17}$ This occurs typically on days with higher sunshine duration and average temperatures. The amount of allergic conjunctivitis during the surveillance period was $11 \%$ of all encoded H10.x diagnoses. Another explanation for this correlation is possibly the overall correlation of patient volume and increasing sunshine duration or temperature.

The literature describes a positive correlation between the incidence of iridocyclitis and cold weather or extreme weather changes. ${ }^{7,8} \mathrm{We}$ were not able to confirm this relationship.

No studies exist concerning the weather and the incidence of corneal abrasion. In this investigation, we have not found a correlation between the incidence of this condition and the weather, although an association with males was found (visits per week [male:female], 208:40). Because of the high standard deviation of the results for corneal abrasion, a Wilcoxon analysis could not be performed. We have however established that the difference between males and females for corneal abrasion is statistically significant by using a Brown-Forsyth test $(P<0.01)$. Overall, $17 \%$ of the cases of corneal abrasion were encoded as an accident occurring at work (average 6\%). With regard to the higher numbers of traumatic formation, this might explain the higher incidence in males, as is the case in corneal foreign bodies.

\section{Conclusion}

During the 18-month observation period, we identified a positive correlation between the weekly overall patient volume or the incidence of two ophthalmological diagnoses (foreign body in cornea and conjunctivitis) and the meteorological 
data. The positive correlation in each case was statistically significant for the weekly sunshine duration and the weekly average temperature. Moreover, a higher incidence was detected for foreign body in cornea in males compared with females. The results of this data analysis may help to explain the influence of external conditions on the health of a population. This knowledge can be used in the future for improved and weather-dependent staffing of emergency rooms.

\section{Disclosure}

The authors report no conflicts of interest in this work.

\section{References}

1. Gerber Y, Jacobsen SJ, Killian JM, Weston SA, Roger VL. Seasonality and daily weather conditions in relation to myocardial infarction and sudden cardiac death in Olmsted County, Minnesota, 1979 to 2002. J Am Coll Cardiol. 2006;48(2):287-292.

2. Vencloviene J, Babarskiene R, Dobozinskas P, Siurkaite V. Effects of weather conditions on emergency ambulance calls for acute coronary syndromes. Int J Biometeorol. 2015;59(8):1083-1093.

3. Vencloviene J, Babarskiene RM, Dobozinskas P, Sakalyte G, Lopatiene K, Mikelionis N. Effects of weather and heliophysical conditions on emergency ambulance calls for elevated arterial blood pressure. Int J Environ Res Public Health. 2015;12(3):2622-2638.

4. Sun X, Sun Q, Yang M, et al. Effects of temperature and heat waves on emergency department visits and emergency ambulance dispatches in Pudong New Area, China: a time series analysis. Environ Health. 2014; 13:76.

5. McMichael AJ. Extreme weather events and infectious disease outbreaks. Virulence. 2015;6(6):543-547.

6. Yang AC, Fuh JL, Huang NE, Shia BC, Peng CK, Wang SJ. Temporal associations between weather and headache: analysis by empirical mode decomposition. PLoS One. 2011;6(1):e14612.

7. Stan C. Influenta factorilor meteorologici in timpul iernii asupra frecventei de aparitie a iridociclitelor acute endogene. [The influence of meteorological factors in wintertime on the incidence of the occurrence of acute endogenous iridocyclitis]. Oftalmologia. 2000;52(3):16-21. Romanian.
8. Jedrzejewski D. Badania doswiadczalne i kliniczne nad wyjasnieniem wplywu niskiej temperatury na ustepowanie zmian zapalnych teczowki i ciala rzeskowego. [Experimental and clinical studies on the effect of low temperature on regression of inflammatory changes in iridocyclitis]. Klin Oczna. 1982;84(5-6):139-141. Polish.

9. Kortum KU, Muller M, Babenko A, Kampik A, Kreutzer TC. Entwicklung eines augenarztlichen klinischen Informationssystems fur bettenfuhrende Augenkliniken. [Development of an ophthalmological clinical information system for inpatient eye clinics]. Ophthalmologe. 2015;112(12):995-1001. German.

10. Kealey B, Howie A. ICD-10 is coming an update on medical diagnosis and inpatient procedure coding. Minn Med. 2013;96(11):48-50.

11. Weather Data for Airport Munich (File ID 1262); 2016. Available from: $\mathrm{ftp}: / / \mathrm{ftp}-\mathrm{cdc} . \mathrm{dwd}$.de/pub/CDC/observations_germany/climate/daily/k1/ historical. Accessed April 15, 2016.

12. Horanont T, Phithakkitnukoon S, Leong TW, Sekimoto Y, Shibasaki R. Weather effects on the patterns of people's everyday activities: a study using GPS traces of mobile phone users. PLoS One. 2013;8(12): e81153.

13. Chan CB, Ryan DA. Assessing the effects of weather conditions on physical activity participation using objective measures. Int J Environ Res Public Health. 2009;6(10):2639-2654.

14. Mischke J, Wingerter $C$ [webpage on the Internet]. Frauen und Männer auf dem Arbeitsmarkt. 2012. Available from: https://www.destatis. de/DE/Publikationen/Thematisch/Arbeitsmarkt/Erwerbstaetige/ BroeschuereFrauenMaennerArbeitsmarkt0010018129004.pdf? blob=publicationFile. Accessed June 14, 2016.

15. Bielory L. Allergic conjunctivitis and the impact of allergic rhinitis. Curr Allergy Asthma Rep. 2010;10(2):122-134.

16. Jalbert I, Golebiowski B. Environmental aeroallergens and allergic rhino-conjunctivitis. Curr Opin Allergy Clin Immunol. 2015;15(5): 476-481.

17. Rosario N, Bielory L. Epidemiology of allergic conjunctivitis. Curr Opin Allergy Clin Immunol. 2011;11(5):471-476.
Clinical Ophthalmology

\section{Publish your work in this journal}

Clinical Ophthalmology is an international, peer-reviewed journal covering all subspecialties within ophthalmology. Key topics include: Optometry; Visual science; Pharmacology and drug therapy in eye diseases; Basic Sciences; Primary and Secondary eye care; Patient Safety and Quality of Care Improvements. This journal is indexed on Submit your manuscript here: http://www.dovepress.com/clinical-ophthalmology-journal

\section{Dovepress}

PubMed Central and CAS, and is the official journal of The Society of Clinical Ophthalmology (SCO). The manuscript management system is completely online and includes a very quick and fair peer-review system, which is all easy to use. Visit http://www.dovepress.com/ testimonials.php to read real quotes from published authors. 